\title{
Word Formation Strategies and Semantic Relations in Football Discourse
}

\author{
Sade Olagunju PhD \\ English Unit, Department of General Studies, Ladoke Akintola University of Technology, \\ P.M.B. 4000, Ogbomoso, Nigeria
}

\begin{abstract}
This paper explores the word formation processes and semantic relations in football discourse. It aims to investigate the type of word formation and semantic relations of words that are associated with the written football discourse. Knowledge of word formation with semantic relations of words is very relevant in enriching or expanding vocabulary power in English. It facilitates the learning of English words and aids effective communication. Application of word formation knowledge can solve the problem of inadequate or limited vocabulary power among the learners and users of English language in a second language situation. English as Second Language (ESL) learners cannot acquire vocabulary and affixes knowledge in the classroom alone, adequate attention need to be paid to using materials from the media, that is both print and electronic media. This will assist in improving their vocabulary development. There are different types of word formation strategies in English namely: blending, clipping, back formation, coinage, reduplicatives, borrowing, compounding, acronyms and abbronyms. At the lexico-semantic level, we have synonyms, antonyms and lexical repetition.
\end{abstract}

Keywords: word formation, vocabulary, media, affixation, abbronyms, synonyms, discourse

DOI: $10.7176 /$ RHSS/9-8-07

Publication date: April $30^{\text {th }} 2019$

\section{Introduction}

Word formation in English has its root in structural morphology. Morphology is the branch of linguistic that deals with words, their internal structure, and how they are formed. Structural morphology is a branch of morphology that has its own organization in analyzing. It has four components, namely, list of morpheme, word formation process, morphophonological process and dictionary. The first task is identifying all morphemes from the data that had been collected. Second task is word formation which explains how morphemes of a language arranged in a group to form a word. So 'word' is something complex that needs to be analysed and described at the morphological, syntactic and lexico-semantic levels.

\section{Morpheme}

The term morpheme is used to refer to the smallest unit that has meaning or serves a grammatical function in a language. That is, morpheme is the smallest meaningful unit of a language (Lyons 1974:81). Morphemes are the atoms with which words are built, as the smallest difference in the shape of a word that correlates with the smallest difference in a word or sentence meaning or in grammatical structure. Morpheme is the minimal meaningful units that are used to form words. -Morphemes are divided into two classes namely; free and bound morphemes

\subsubsection{Free Morpheme}

Free morpheme can stand alone as independent words like tree, boy, girl, run etc. A free morpheme is also called 'lexical base'.

\subsubsection{Bound morpheme}

Bound morphemes are those morphemes that cannot stand alone, but must be attached to a lexical base. Bound morphemes, also called affixes and they are classified according to their position while the process is called affixation. Two types of affixation exist in English in respect to English word: prefixation and suffixation

\subsubsection{Prefixation}

Prefixation is adjoining of a prefix to the free morpheme. A prefix is a bound morpheme affixed to the beginning of a word. Prefixes change the meanings of the word to which they are added but do not generally alter the wordclass of the base ( Quirk and Greenbaum 1973:431) .

\subsubsection{Suffixation}

Suffixation refers to the placing of a bound morpheme at the end of a word. Quirk and Greenbaum (1973: 436441) place emphasis on the tendency of suffices to change or retain word classes. Suffixes can be inflectional when they retain the word classes after adding affixes to the end of the word. Examples are scores, states, matches etc. Derivational affixes result in change in word class or meaning of a word. This implies that a noun could be derived from a base morpheme which belong to the class of a verb; an adjective could also be derived from a noun,etc. Inflectional affixes on the other hands change the word class.Example of inflectional affixes are cat- cats, boyboys, etc. 


\subsection{The Word}

The word is a unit that is higher than the morpheme in this hierarchy. Words are classified according to the functions they perform in the phrase. The English words are categorized into grammatical words and content/lexical words. Grammatical words include articles, demonstratives, pronouns, prepositions, conjunctions, and auxiliary verbs. Quirk and Greenbaum tagged this category as 'closed system item' because they are fixed and not extendable. They cannot be extended by creation of additional members unlike the lexical/content words which allow new items. They are called open class item because they are indefinitely extendable and have dictionary meanings. The content/lexical words are nouns, verbs, adjectives, adverbs (Quirk and Greenbaum 1973).

\subsection{Compounding}

This is a process of word formation involving the combination of two or more roots to give a new word. Bauer (1973) suggests that a compound may be defined as a lexeme containing two or more potential stems that has not subsequently been subjected to derivational process. Compounding is a process of word formation that involves combining complete word forms into a single compound form. A compound word is formed from a combination of free morphemes. Quirk and Greenbaum (1973) define a compound as a unit consisting two or more bases. These compound words can be made of many combinations but the most frequent combination is those of noun and noun. This is the largest sub-grouping of compounds. Another thing to note about compounds is that they can combine words of different parts of speech. The noun-noun compounds, which is probably the most common part of speech combination, but there are others, such as adjective-noun (dry run, blackbird, hard drive), verb-noun (pick-pocket, cut-purse, lick-spittle) and even verb-particle (where 'particle' means a word basically designating spatial expression that functions to complete a literal or metaphorical path), as in run-through, hold-over. Sometimes these compounds are different in the part of speech of the whole compound vs. the part of speech of its components. Note that the last two are actually nouns, despite their components. Compounds may be compositional, meaning that the meaning of the new word is determined by combining the meanings of the parts, or noncompositional, meaning that the meaning of the new word cannot be determined by combining the meanings of the parts. For example, a red card is a card that is red. However, a goal mouth does not mean a mouth of the goal in the real sense of the word but the area in front of the goal.

\subsection{Abbronyms}

The term abbronyms was coined by Odebunmi (2001) to explain abbreviation and acronyms in the light of the discovery that the two terms are difficult to tell from each other. Abbronyms have been defined as letters representations of a group of letters, words or phrases, which may or may not be pronounceable (Odebunmi 2001:35). There are two types of abbronyms, viz simple and complex abbronyms. Simple abbronyms are formed from initial letters of a terminiology, a word or a phrase with or without grammatical words. Abbronyms can be termed as complex when their structures are not easily predictable from their full forms. Abbronyms are used in professional settings to economise the usually long terminology in the fields of science and others such as engineering, agriculture, medicine; and sport communication.

\section{Data Resources}

The football World Cup 2010 held in South Africa provides a wide range of information resources most especially for both electronics and print media. It serves as great resources for scholars from different fields or disciplines to look at the genre of sports as part of wholistic approach to the process of globalisation. The primary source of data is the reports of the mentioned world cup. Texts were purposively selected from the reports of the 2010 world cup reported by Nigerian newspapers. Three Nigerian newspapers selected are Sporting Life Complete Sports, and Soccer Star. These newspapers were categorized as Texts A, B and C respectively. 30 lead articles were purposively selected from each of the newspapers during the period of one month World cup tournament. Altogether, the data comprises of 90 lead articles. The secondary source of data includes book, journal and the internet. The contents of the selected articles were read and analysed.

\subsection{Analysis of Data and Discussion of Results \\ 4.1 Word Formation Strategies in the Data}

Not all the word formation types featured in the data. Below are the few but significant types of word formation that characterized the written football texts selected for the study.

\subsubsection{Compound Words}

Compound words are used across the data. Some are with hyphens and some are without. Most of the compound words are lexical items associated with football sport. That is, they are mostly soccer terms or what may be referred to as football jargon. Examples of these are compounds like free-kicks, off side, second-half, side netting, football, yellow card, red card, goalkeeper, teammate, first half, score line, touch line, match fixer, free-scoring, gamechanging, runners-up, center-back, full back, among others. The frequency and percentage distribution of 
compound words in Texts A-C are presented in the table below.

\begin{tabular}{|l|l|l|}
\hline Text & Frequency & Percentage Distribution \% \\
\hline Text A & 179 & 33.46 \\
\hline Text B & 198 & 37.01 \\
\hline Text C & 158 & 29.53 \\
\hline Total & 535 & 100 \\
\hline
\end{tabular}

Table 1: Frequency and Percentage Distribution of Compounding in Texts A-C

The table shows the frequency and percentage distributions of compounding used across the data. These compound words are formed from different word classes in Texts A-C. It can be inferred from the table that compounding has the highest rate of occurrence in Text $\mathrm{B}$ with $37.53 \%$ and next to it in terms of frequency is Text A where compounding has $33.46 \%$ while Text $\mathrm{C}$ has just $29.53 \%$ of the occurrence of compounding. Below are the examples of compounding.

\begin{tabular}{|l|l|l|}
\hline S/N & Word & Individual classes \\
\hline 1 & Football & Noun + noun \\
\hline 2. & Corner-kick & Noun + verb \\
\hline 3 & World Cup & Noun + noun \\
\hline 4. & Super Eagles & Adjective + noun \\
\hline 5 & Midfielder & Adjective + noun \\
\hline 6 & First-half & Adjective + noun \\
\hline 7 & Second-round & Adjective + noun \\
\hline 8 & Post-match & Adjective + noun \\
\hline 9 & Knock-out & Noun + adjective \\
\hline 10 & Quarter-final & Adjective + adjective \\
\hline
\end{tabular}

Table 2: Examples of Compounding and the Word Classes That Realises Them

\subsubsection{Abbronyms}

There are instances of the use of abbronyms in Texts A-C. They are realised across the the data. The abbronyms used are largely associated with football and government agencies or parastatals. The most salient and most frequently used abbronym is FIFA- Federation International Football Association. In Text A, abbronyms had the highest frequency of $37.33 \%$ followed by Text B where the frequency is $32.53 \%$ and Text $\mathrm{C}$ had the lowest frequency of abbronym of $30.14 \%$. Examples of the abbronyms and their complete forms are given subsequently.

\begin{tabular}{|l|l|l|}
\hline S/N & Abbronyms & Complete Forms \\
\hline 1. & FIFA & Federation Internationale de Football Association \\
\hline 2. & NFF & Nigerian Football Federation \\
\hline 3. & CAF & Confederation of African Football \\
\hline 4. & NSC & National Sports Commission \\
\hline 5. & USA & United States of America \\
\hline 6. & EFCC & Economic and Financial Crime Commission \\
\hline 7. & FC & Football Club \\
\hline 8. & PTF & Presidential Task Force \\
\hline 9. & BBC & British Broadcasting Coporation \\
\hline 10. & MDGs & Millenium Development Goals \\
\hline 11. & IFAB & International Football Association Board \\
\hline 12. & UEFA & Union of European Football Associations \\
\hline
\end{tabular}

\section{Table 3: Examples of Abbronyms and Complete Forms Across Texts}

\subsection{Lexical Relationship}

Lexical relationships in the football reports include antonymy, synonymy, collocation and lexical repetition. These are relationships of meaning holding between words and sentences in language. The next section is devoted to the explanation of each of the lexical relations identified in the texts.

\subsubsection{Antonymy}

Antonymy implies the relationship of oppositeness within or across sentences. It is the concept of oppositeness. Unlike synonyms, antonyms could be true or exact. Antonyms in the data are mostly complementary and relational opposites. Examples of antonyms are given below.

A win there would see then play either Uruguay, South Korea in the quarter- finals and the chance of becoming the first African country to reach the semi- finals Cameroun and Senegal having reached the last eight in 1990 and 2002 respectively. (Text A30, Sporting Life, June 26, 2010) 
My brother, I have been in the national team for the past 16 years and I know the difference between white and black. (Text B11, Complete Sports, June 28, 2010)

It is a must win for us against Greece, said locomotive Moscow stroker Osaze Odemwingie after the 1-0 loss to Argentina on Sunday. (Text C3, Soccer Star, June 14, 2010)

Nigeria, who have now gone five defeats and a draw since their last win at the World Cup in 1998, take on Greece in Bloemfontein on Thursday. (Text B15, Complete Sports, June 15, 2010)

With the goalkeeper ratings we try to strop out effect of the defense- it is not how many saves he makes but his performance once you have assessed how good/bad the defense is. (Text C6, Soccer Star, June 12, 2010).

\subsubsection{Synonymy}

Synonymy is the relationship of similar lexical items or lexemes. It is a concept of similarity, that is, sameness of meaning of words. Although there are no absolute or exact synonyms like antonyms because of collocational restriction but there must be some degree of nearness or proximity of meaning. There are no two terms with completely identical meaning. Examples of synonyms are given below.

6

"A new beginning, a new start in a new country promises so much of a challenge for me", Martins declared. (Text A29, Sporting Life, July 10, 2010)

Till now it is still confounding, bizarre and baffling how a country that lost its first two group matches could still have qualified by winning the third and last with any score line. (Text B5, Complete Sports, June 26, 2010)

Today will mark the end of the ranging psychological warfare for the past few months as both teams file out in a titanic battle. (Text C6, Soccer Star, June 12, 2010)

\subsection{Lexical Collocation}

There are instances of fixed collocation in the data. These are associated with the word 'goal'. They are realised in Texts A-C. The word 'goal' is very significant when dealing with the language of football. It determines winning and losing the game. It is considered important to look into this phraseological units that are associated with football game because winning the tournament attracts rewards most times, while in some football league competitions, loosing attracts relegation of the team(s) involved. Examples of fixed collocation associated with the lexeme 'goal' will be given subsequently.

Shot at goal is an example of fixed collocation. It is used in football association. The word shot is a noun form of shooting. It is a specialised kicking technique mainly used by 'forwards'. Shooting is a way for goals to be scored. It is done using feet or using the head, that is, heading the ball. The purpose of shooting the ball is to get the ball past the goal line. Although some shots may be made in order to win corners or force the keeper to defect the ball into the path of a team mate. This may be the case if scoring directly from the shot seems unlikely. A failed 'shot at goal' is called attempt. Below are examples from the data. 9

Holland's first shot at goal came when Dirk Kuyt scutted a 30-yard effort after Sergio Busquet to control a simple square pass, but the Liverpool wide man's effort was easily gathered by Iker Casillas. (Text A16, Sporting Life, July 12, 2010)

"I was thinking of passing the ball when I should have shot at goal. The way Obafemi Martins was shouting on me to pass to him the ball, I thought he was in a better position. I lost concentration and the chance," he said. "Next time, I will just go for goal". (Text C3, Soccer Star, June 14, 2010)

Face of goal is another example of fixed collocation associated with goal. It refers to the open front of the goal. Below is an example from the data.

11

Iniesta was perhaps lucky not to join them as the game once again threatened to deteriorate, his foul on Sneijder giving Robben the chance to swing in a free-kick toward Heitinga. The defender sent a header just across the face of goal, but had been flagged offside any case. (Text A16, Sporting Life, July 12, 2010) 
Concede a goal - This refers to the opposite of score a goal. To concede a goal means inability to stop an opposition team or player from scoring. The player or team in the opposition gets the goal or point. After a goal is scored, the team which conceded the goal will kick-off to restart play. The team that scores the highest numbers of goal(s) wins the game. In football antonyms, 'score a goal' and 'concede a goal' are associated with winning and losing the game. Examples are presented below.

Asked if he had corrected the lapse of conceding a goal from set-piece against Argentina, Lagerback said: "We have been working on how to defend set-pieces. But this time around, we have taught the players other forms of defending it especially after what happened against Argentina. Defending set-pieces would not be a problem for us against Greece. I can assure you. (Text A17, Sporting Life, July 17, 2010)

We didn't play as well in attack as we'd hoped, but it's good that we only conceded the one goal. (Text B1, Complete Sports, June 17, 2010)

After a two year with West Broom, Kanu joined Portsmouth in 2006 and he played in two FA cup finals, scoring the winning goal against Cardiff in the 2008 show piece at Wembley. (Text B19, Complete Sports, June 26, 2010)

May be that is still surprising, He had made 20 saves, which was the second highest of any keeper but had conceded five goals, which was equal third worst. (Text C5, Soccer Star, July 8, 2010)

16

"I'm very positive, If we could just concede a goal against the big Argentina attack, it should be easier for us against the other teams. We just have to concentrate and score goals. (Text C3, Soccer Star, June $14,2010)$

\subsection{Lexical Repetition}

Lexical repetition refers to a concept of semantic relatedness in sentences or texts. It involves repeating the same lexical item many times (i.e recurrence) wether across sentence boundaries or within the same sentence. It is an instance where 'a lexical item that has already occurred in a text is repeated with no greater alteration than is entirely explicable in terms of a closed grammatical paradigm' (Hoey 1991:53)

17

We can talk about referencing decisions which, when you looked at the after the game, you could say were perhaps not good decisions. (Text B9, Complete Sports, July 8, 2010)

The reforms should include a new leadership for the football association, a permanent coach for the national team, a new generation of players for the national team, and a return to the football development as a focus of Nigerian football for some years to come. (Text B5, Complete Sports, June 26, 2010)

If it was Nigeria coach that failed woefully at the World Cup, they will sack him form South Africa, But the NFF are begging the man because he man because he is ths only good coach in the World. (Text A22, Sporting Life, July 3, 2010)

According to FIFA: "if Argentina beats Greece and Korea Republic beats or draws with Nigeria, the South American will finish top and the Asians second". (Text C1, Soccer Star, June 20, 2010)

A defender scored the goal that got Spain its first World Cup final, and any one of its fine substitutes could summoned to score the defining goal in its history. (Text A7, Sporting Life, July 11, 2010)

"Pianear has grown this year, he was usually a very busy player where the final ball was missing a little bit, but this year he has gained in personality and he has kept his work rate, so he has been much more efficient" (Text A1, Sporting Life, June 16, 2010)

"We can’t lose; we must not lose" (Text A3, Sporting Life, June 22, 2010)

"There must be a new beginning in the country when it comes to football" (Text A22, Sporting Life, July $3,2010)$

"I wish he was with us during the Nations Cup in Angola, in fact, the Amodu days was a waste" (Text 
B16, Complete Sports, June 15, 2010)

"We just have to step up our game and see that we win our next match against South Korea" (Text B13, Complete Sports, June 19, 2010)

27

'We all know what we must do on Thursday, it's victory or nothing and I'm glad we're ready to fire from all cylinders. Hopefully, the result will go our way' (Text B1, Complete Sports, June 17, 2010)

"Our target now is to focus on the next matches to book qualification to the next round of the competition" (Text C2, Soccer Star, June 17, 2010)

"Some players from the Nigerian team are actually involved in some form of manipulations" (Text C9, Soccer Star, July 10, 2010)

"We were unlucky not to get a point in the end" (Text C8, Soccer Star, June 14, 2010)

Quotation marks could be single or double depending on the preference of the writer. But if both are used within the same expression, it could be the case where there is a quotation within a quotation. None of such is however discovered in the texts.

\subsection{Conclusion}

The study has a pedagogical implication. The study will assist learners to get mastery and command of vocabulary by using words effectively and productively for social interaction and communication. It will be very useful for developing a register for football reporting. The study can be applied to the understanding of genre analysis and functional approaches of other discourses in other fields. It can also be applied to the teaching of sports and media communication.

\section{References}

Bauer, L. (1973) English Word Formation. Cambridge: Cambridge University Press.

Hoey, M. (1991) Patterns of Lexis in Text. Oxford: Oxford University Press

Lyons, J. (1974) Introduction to Theorectical Linguistics. Cambridge: Cambridge University Press.

Odebunmi A.( 2001) The English Word and Meaning: An Introductory Text. Ogbomoso: Critical Sphere.

Okeke, C. and Obasi, G. (2014) Word Formation Process In Nigeria Short Messages Service. Theory and Practice in Language Studies. Finland: Academy Publisher Pp 2215-2222

Quirk, R. and Greenbaum, S. (1973) A University Grammar of English. Hong Kong: Longman 


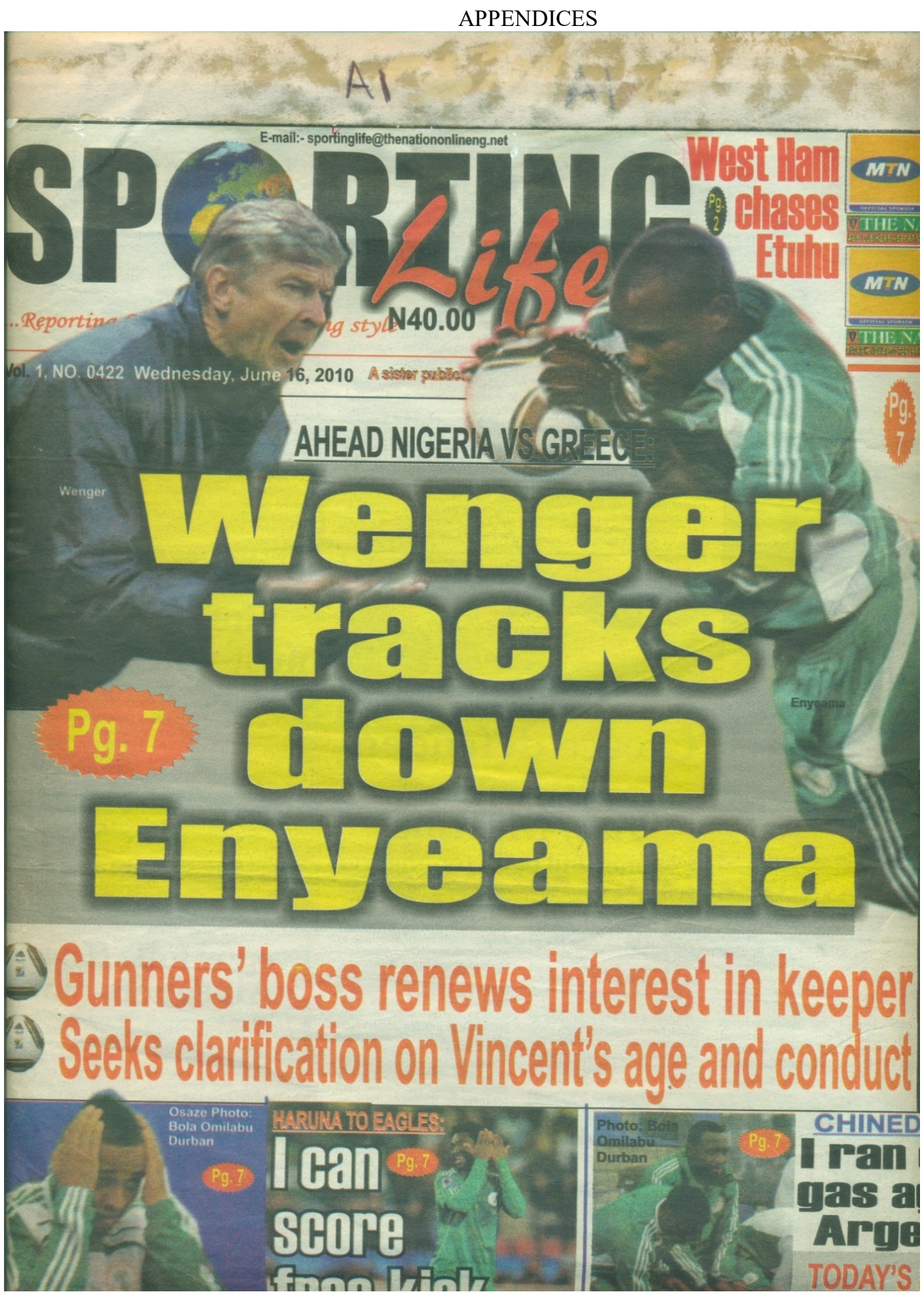




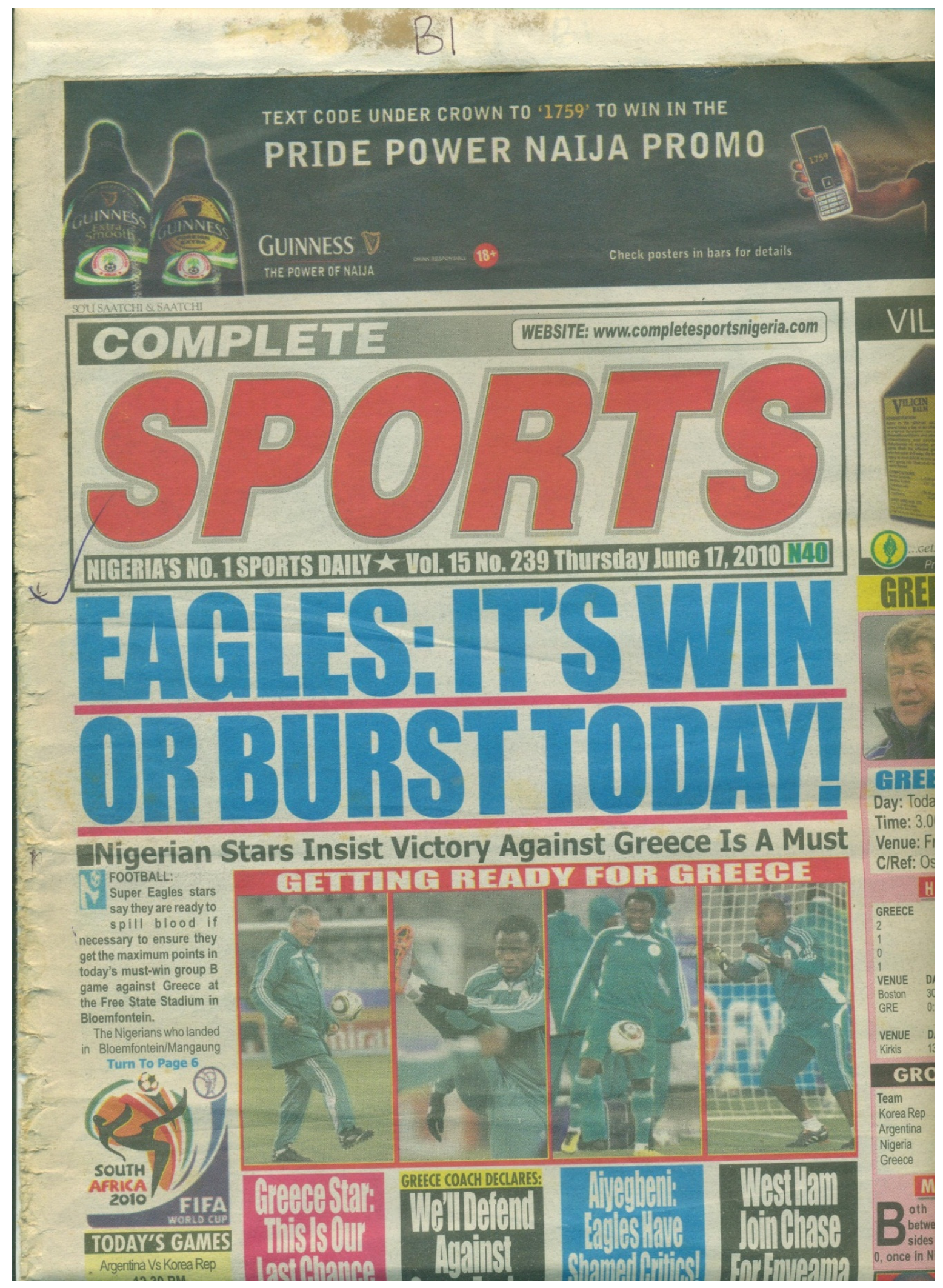




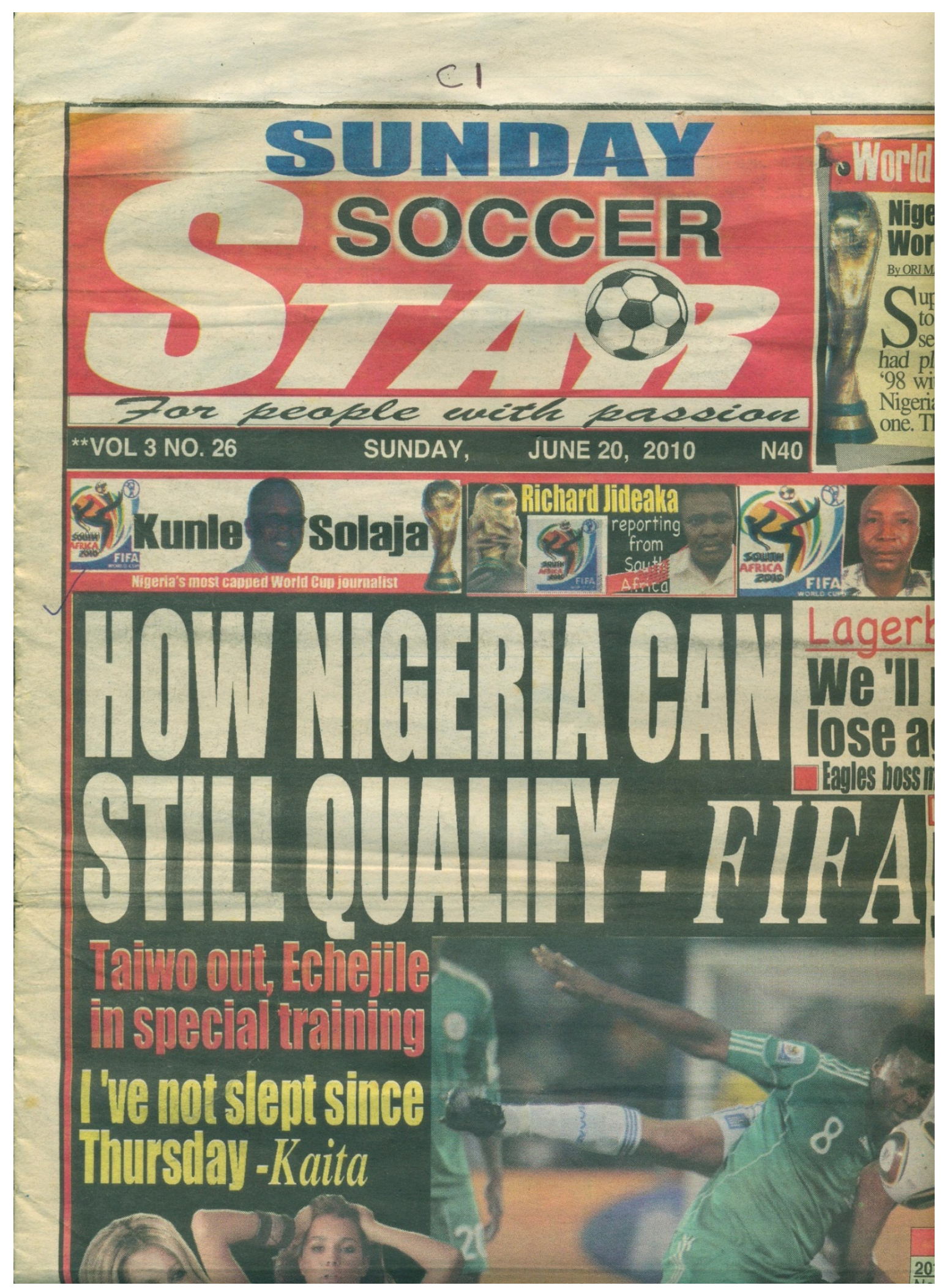

